OPEN ACCESS

Edited by:

George Smith,

Temple University School of

Medicine, USA

Reviewed by:

Eduardo Fernandez,

Universidad Miguel Hernández de

Elche, Spain

Marianna Foldvari,

University of Waterloo, Canada

*Correspondence:

Philip J. Horner

pjhorner@houstonmethodist.org

Received: 13 July 2016 Accepted: 11 October 2016

Published: 01 November 2016

Citation:

Tan J-KY, Sellers DL, Pham B,

Pun SH and Horner PJ

(2016) Non-Viral Nucleic Acid Delivery Strategies to the Central

Nervous System.

Front. Mol. Neurosci. 9:108. doi: 10.3389/fnmol.2016.00108

\section{Non-Viral Nucleic Acid Delivery Strategies to the Central Nervous System}

\author{
James-Kevin Y. Tan ${ }^{1}$, Drew L. Sellers ${ }^{1}$, Binhan Pham ${ }^{1}$, Suzie H. Pun ${ }^{1}$ \\ and Philip J. Horner ${ }^{2 *}$ \\ 'Department of Bioengineering and Molecular Engineering \& Sciences Institute, University of Washington, Seattle, WA, USA, \\ ${ }^{2}$ Center for Neuroregenerative Medicine, Houston Methodist Research Institute, Houston, TX, USA
}

With an increased prevalence and understanding of central nervous system (CNS) injuries and neurological disorders, nucleic acid therapies are gaining promise as a way to regenerate lost neurons or halt disease progression. While more viral vectors have been used clinically as tools for gene delivery, non-viral vectors are gaining interest due to lower safety concerns and the ability to deliver all types of nucleic acids. Nevertheless, there are still a number of barriers to nucleic acid delivery. In this focused review, we explore the in vivo challenges hindering non-viral nucleic acid delivery to the CNS and the strategies and vehicles used to overcome them. Advantages and disadvantages of different routes of administration including: systemic injection, cerebrospinal fluid injection, intraparenchymal injection and peripheral administration are discussed. Non-viral vehicles and treatment strategies that have overcome delivery barriers and demonstrated in vivo gene transfer to the CNS are presented. These approaches can be used as guidelines in developing synthetic gene delivery vectors for CNS applications and will ultimately bring non-viral vectors closer to clinical application.

Keywords: central nervous system, delivery, in vivo, non-viral, nucleic acid

\section{INTRODUCTION}

The incidence of neurological diseases and injuries is increasing with the rising life expectancy (Mattson and Magnus, 2006). Nucleic acid therapeutics, such as genes and small interfering RNA (siRNA) oligonucleotides have emerged as a promising treatment strategy to preserve neuron function, enhance neurogenesis and prevent the progression of neurological diseases. The delivery of nucleic acids encoding brain-derived neurotrophic factor (Huang et al., 2012a), epidermal growth factor (Sugiura et al., 2005), fibroblast growth factor-2 (Matsuoka et al., 2003), Huntingtin (Burgess et al., 2012), neurogenin-2 (Zhang et al., 2013; Masserdotti et al., 2015), insulin growth factor-1 (Kaspar et al., 2003), and vascular endothelial growth factor (Dodge et al., 2010) have been shown to increase neuron regeneration or delay the progression of neurological diseases in mice, rats and gerbils. Targeting gene delivery vehicles to the appropriate cells and proper protein regulation remain the primary challenges to making these pathways feasible. While viral vectors such as the adeno-associated virus have typically been used clinically, interest in non-viral nucleic acid delivery remains high due to lower safety concerns, greater customizability and an ease in manufacturing (Pack et al., 2005; Burke et al., 2013). In fact, the number of synthetic vectors used in gene therapy clinical trials has been steadily increasing over the last 10 years (Gene Therapy Clinical Trials Worldwide, Wiley). 
With neurological diseases specifically affecting different parts of the brain and even sub-phenotypes of neural cells, the route of administration is a crucial aspect of nucleic acid delivery. Intraventricular injection places therapeutics closer to the subventricular zone, one of the stem cell niches of the brain, whereas localized intraparenchymal injections may be used to target a specific part of the brain where neurodegeneration is occurring or at the location of disease (e.g., brain tumor). In this focused review, we explore the barriers facing in vivo nucleic acid delivery and highlight the recent synthetic vehicles and different strategies that have overcome these challenges to deliver nucleic acids to the central nervous system (CNS). First, we briefly discuss nucleic acid protection and targeting the CNS since these strategies apply to any route of administration. In later sections, we discuss the common routes of administration and the specific barriers and vehicular solutions accompanying each method. While a wide variety of delivery vehicles have been applied to nucleic acid CNS delivery, we primarily focused on lipidic and polymeric vehicles with a few selected examples of inorganic delivery vehicles.

\section{Nucleic Acid Protection}

With any route of administration, nucleic acids are susceptible to chemical degradation and clearance from the body due to the presence of extracellular nucleases and the immune system (Abdelhady et al., 2003). While naked nucleic acid delivery is feasible, carrier-mediated delivery has the potential to be more efficient by protecting nucleic acids and chaperoning nucleic acids through the extracellular and cellular barriers to gene delivery (Figure 1). Thus, this focused review focused on carrier-mediated delivery of nucleic acids. Typically, negatively charged nucleic acids are complexed and condensed with cationic, synthetic materials which allows for nucleic acids to remain hidden and avoid degradation (Pack et al., 2005). Common complexation agents used for in vitro gene transfer include cationic polymers such as polyethylenimine (PEI), which electrostatically bind to nucleic acids to form "polyplexes," or polymer-nucleic acid complexes. Similarly, cationic lipids can also be used to complex nucleic acids to form "lipoplexes". Another method of enhancing stability is by modifying the nucleic acid itself so that it avoids recognition and degradation. For example, altering the ribose moiety and introducing $2^{\prime}$-fluoro and phosphorothioate near the terminal region of siRNA duplexes enhanced stability and prolonged siRNA half-life in vivo (Wang et al., 2008).

Despite the protection afforded to nucleic acids by electrostatic complexation, these cationic complexes are still subject to challenges such as aggregation, toxicity, premature sequestration by phagocytic cells, and non-specific interaction with cell membranes and serum proteins (Morille et al., 2008). When intravenously administered, PEI, one of the most effective transfection agents in vitro, causes severe toxic side effects due to polyplex aggregation and strong electrostatic interactions with cell membranes, proteins and the extracellular matrix (Al-Dosari and Gao, 2009). To overcome

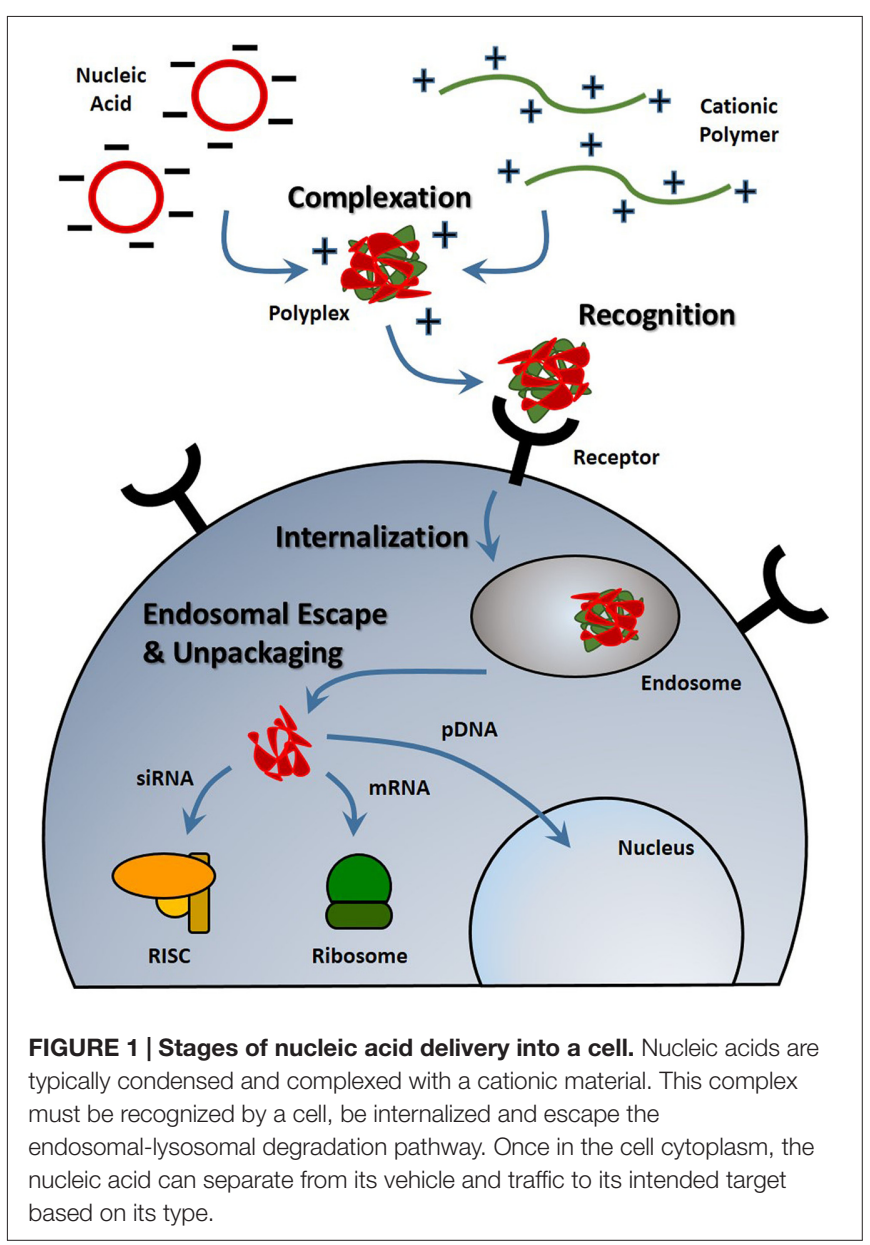

these challenges, shielding strategies have been developed to hide nucleic acid delivery vehicle by moieties like poly(ethylene glycol) (PEG) and albumin (Lu et al., 2006; Laga et al., 2012).

PEG, a biocompatible, hydrophilic polymer, is commonly used as a shielding agent for nanoparticles (Immordino et al., 2006). By creating a barrier around the complex, it was previously believed that PEG prevents the adsorption of proteins (Pombo García et al., 2014). However, recent studies suggest that PEGylation of nanoparticles results in preferential binding of clusterin, a chaperone protein that binds to hydrophobic domains of unfolded proteins and prevents non-specific binding (Schöttler et al., 2016). When conjugated to delivery vehicles, PEG has been shown to improve the stability and increase the circulation half-life of polyplexes, liposomes and other types of vectors. For example, when conjugated to PEI, PEG prevented the aggregation of PEI-plasmid DNA complexes in fetal bovine serum-enhanced media, resulting in complexes that could circulate long enough for observed localization in the brain (Son et al., 2011). With encapsulation in PEGylated liposomes, PEI-oligonucleotide complexes were able to circulate substantially longer and had plasma concentrations significantly higher than naked complexes after $60 \mathrm{~min}$ (Ko et al., 2009). By any route of 
administration, protecting delivery vehicles with a shielding agent minimizes aggregation and premature sequestration and can increase the distribution of the nucleic acids to desired cells.

\section{Targeting the CNS and Neuronal Cells}

Nevertheless, prolonged stability and circulation is not sufficient for substantial nucleic acid delivery to the brain and spinal cord because the nervous system is protected by barriers that grossly prevent the access of therapeutics (Barchet and Amiji, 2009). Cells of the CNS can potentially be accessed through several contact points including: (1) the blood system; (2) the cerebral spinal fluid (CSF) in the ventricles or lumbar space; (3) intraparenchymal fluid in the extracellular space; or (4) nerve endings that extend outside of the nervous system (Cipolla, 2009). The nervous system is sequestered behind a barrier system composed of vascular tight junctions and glial elements that ensheath the blood supply producing a blood-brain and blood-spinal cord barrier (BBB and BSCB, respectively; Banks, 2016). Each of these compartments represent a potential entry point as well as unique challenges for neuronal targeting. Vehicles for systemic delivery must utilize a mechanism that will facilitate penetration and uptake across the BBB or BSCB (Spencer and Verma, 2007; Tobinick, 2016). Within the brain, paracellular flow of neuro-active cytokines is controlled by pulsation of the blood vessels that mechanically drives a peristaltic movement of extracellular fluid (Johanson et al., 2011; Iliff et al., 2013). Meanwhile, gene delivery vehicles directly administered into the ventricles need to bind to cells of interest before being washed out of the CNS (Syková and Nicholson, 2008). At the periphery, a vehicle that promotes uptake at nerve termini and retrograde transport must be able to target a neuron for transfection and promote travel along the neuronal cytoskeleleton into the CNS (Hanz and Fainzilber, 2004; von Bartheld, 2004; Medina-Kauwe, 2007; Tarragó-Trani and Storrie, 2007). Consequently, the advent and development of targeting ligands has greatly enhanced the capacity of non-viral vectors to deliver nucleic acids into the CNS.

Drug delivery vehicles have been modified with targeting agents such as peptides, antibodies, proteins and sugars to specifically home therapeutics to desired tissues and cell types. For systemic administration, active targeting is important in directing the accumulation of vehicles at the brain endothelium. One commonly used brain-targeting molecule is transferrin, a glycoprotein that binds to iron. Transferrin receptor is expressed on the brain endothelium and the binding of transferrin-decorated nucleic acid delivery vehicles to these receptors allows for accumulation right outside the brain (Huang et al., 2007).

Vehicles administered directly into brain by intraventricular or intraparenchymal methods can also benefit from active targeting by directing the delivery of nucleic acids to pertinent cells. For example, to more specifically transfect neural progenitor cells, Tet 1 , a peptide that specifically binds to neuronal cells, was conjugated to PEI complexes (Kwon et al., 2010). This Tet1-PEI polymer led to a significantly improved transfection of neural progenitors by targeted complexes over untargeted complexes. Thus, targeting moieties can help deliver nucleic acids to cells and tissues of interest while minimizing non-specific delivery. In addition, targeting ligands can improve the intracellular delivery of nucleic acids since many targeting ligands are endocytosed by cells after binding to its receptor. Decorated macromolecules such as polyplexes and liposomes show enhanced uptake in cells compared to their non-targeted counterparts.

\section{SYSTEMIC DELIVERY}

Intravenous administration is one of the most common routes of administration for macromolecule therapeutics such as nucleic acids and has the advantage of rapid distribution and high bioavailability. However, systemic circulation presents a major challenge for nucleic acid delivery. Naked DNA has poor stability and is rapidly broken down by nucleases, sequestered by the liver, and cleared from circulation with a plasma half-life of mere minutes (Emlen and Mannik, 1984; Kawabata et al., 1995). To prevent premature degradation and prolong circulation, nucleic acids have been complexed with PEGylated cationic materials, such as polymers and liposomes, which act to shield the polyplex and facilitate compact packaging and protection. Targeting ligands conjugated to the synthetic vectors can facilitate recognition of brain endothelium. However, transport into the brain requires crossing the $\mathrm{BBB}$, a tight network of endothelial cells that restricts entry into the brain parenchyma (Gabathuler, 2010). The brain endothelium has a high expression of efflux pumps and transporter proteins that exclude nearly $100 \%$ of large-molecule therapeutics and more than $98 \%$ of all small-molecule drugs (Begley, 2003; Pardridge, 2005). Recent in vivo investigations have focused on transportation across the $\mathrm{BBB}$ and temporarily disrupting the $\mathrm{BBB}$ after systemic administration.

\section{Transport Across the Blood-Brain Barrier}

Strategic selection of brain targeting ligands can result in both recognition of the brain endothelium and facilitated transcytosis across the BBB. This process, called receptor-mediated transcytosis, has been demonstrated with cationic proteins and is believed to be carried out by clathrin-coated pits or caveolae (Hervé et al., 2008; Table 1). After these materials bind to the luminal surface of the brain endothelial cells, vesicular transcytosis is mediated by different proteins and the high concentration of mitochondria in endothelial cells to cause exocytosis at the abluminal surface.

The transferrin receptor is frequently targeted for $\mathrm{BBB}$ transcytosis. After binding the transferrin receptor carrier protein, the transferrin-iron complex is internalized at the apical side of the brain endothelium and is eventually exocytosed at the opposite basal surface. Since transferrin receptor is expressed on the $\mathrm{BBB}$ and transcytoses transferrin, it can be utilized as an uptake pathway into the brain by nucleic acid vehicles functionalized with transferrin. In one example, polyamidoamine (PAMAM) dendrimers were decorated with transferrin by a PEG linker and showed a $\sim 2$-fold higher brain 
TABLE 1 | Properties of effective nucleic acid delivery vehicles.

\begin{tabular}{|c|c|c|c|}
\hline Property & Function & Material examples & Schematic \\
\hline Nucleic acid packaging & $\begin{array}{l}\text { Condense, package, and protect DNA, } \\
\text { RNA, or SiRNA }\end{array}$ & PEI, PLL, PAMAM, liposomes & \\
\hline Stability & $\begin{array}{l}\text { Prevent premature unpackaging and avoid } \\
\text { sequestration and clearance }\end{array}$ & PEG, albumin & \\
\hline Targeting & CNS localization and cell-specific uptake & Peptides, antibodies, proteins & \\
\hline Endosomal escape & $\begin{array}{l}\text { Facilitate release from the endosome to avoid } \\
\text { Iysosomal degradation }\end{array}$ & $\begin{array}{l}\text { Melittin, } \mathrm{pH} \text { sensitive materials, amines } \\
\text { for proton sponge effect }\end{array}$ & \\
\hline Cargo release & $\begin{array}{l}\text { Triggered release or detachment from } \\
\text { nucleic acid }\end{array}$ & Disulfide linkages & \\
\hline
\end{tabular}

uptake and gene transfer compared to PEGylated dendrimers alone (Huang et al., 2007). In another example, transferrin antibodies were used to decorate liposomes that hid plasmid DNA. This system was able to show a 10 -fold greater $\beta$-glucuronidase enzyme activity in murine brains deficient of the protein (Zhang et al., 2008).

Another BBB transcytosis moiety is the rabies viral glycoprotein (RVG) peptide, a 29-amino acid peptide which binds to nicotinic acetylcholine receptors. Modifying the peptide sequence to include nine arginines on the C-terminus allows for complexation with nucleic acids (Kumar et al., 2007). Upon systemic intravenous administration, these complexes were able to transvascularly deliver siRNA to the brain through clathrin- and caveolae-mediated endocytosis by endothelial cells, which lead to extended lives of encephalitic mice. The RVG peptide can also modulate the accumulation of larger vehicles and has delivered macro-structures such as PAMAM dendrimers (Liu et al., 2009), liposomes (Pulford et al., 2010), chitosan nanoparticles (Gao et al., 2014), poly(mannitol-co-PEI) complexes (Park et al., 2015) and exosomes (Alvarez-Erviti et al., 2011) across the BBB and into the brain parenchyma. Other targeting agents have included: angiopep, a peptide that binds to low-density lipoprotein receptor-related protein-1 (Ke et al., 2009); lactoferrin, an iron-binding protein of the transferrin family (Huang et al., 2008, 2010); leptin, a peptide that binds to leptin receptor in different parts of the brain (Liu et al., 2010); chlorotoxin, a scorpion-derived venom that is a specific marker for gliomas (Costa et al., 2013); TGN peptide, a BBB targeting peptide isolated by phage display (Qian et al., 2013); and LIMK2 NoLs peptide, a nucleolar translocation signal sequence derived from the LIM Kinase 2 protein (Yao et al., 2015). Collectively, these targeting agents have shown to facilitate the accumulation of PEGylated PAMAM dendrimers, lysine dendrimers, liposomes, and polymeric polyplexes in the brain.

\section{Blood-Brain Barrier Disruption}

Other methods of systemic nucleic acid delivery focus on temporarily disrupting the $\mathrm{BBB}$ to enhance the diffusion of vehicles into the brain. These strategies can be combined with delivery vehicles to further augment gene transfection. Small molecules, such as mannitol, have been shown to temporarily open the $\mathrm{BBB}$ and allow the penetration of larger molecules into the brain parenchyma. Hypertonic solutions of these molecules is believed to widen tight junctions by shrinking vascular endothelial cells (Rapoport, 2001). Consequently, the co-administration of mannitol with RVG-decorated PEI was able to significantly enhance the distribution of complexes throughout the brain when compared to carriers alone (Hwang et al., 2011).

More recently microbubbles, or gas-filled microspheres, have been coupled with ultrasound as a method to temporarily disrupt the BBB (Meairs and Alonso, 2007; Panje et al., 2013; Rychak and Klibanov, 2014; Figure 2). This process, called sonoporation, creates micropores, permeabilizes cell membranes and breaks up tight junctions as microbubbles act as local enhancers of the ultrasound acoustic energy and cavitate causing local shear flow, microstreams and microjets (Greenleaf et al., 1998; Zhou et al., 2012; Panje et al., 2013). These BBB openings are large enough to allow for the permeation of macromolecules into 


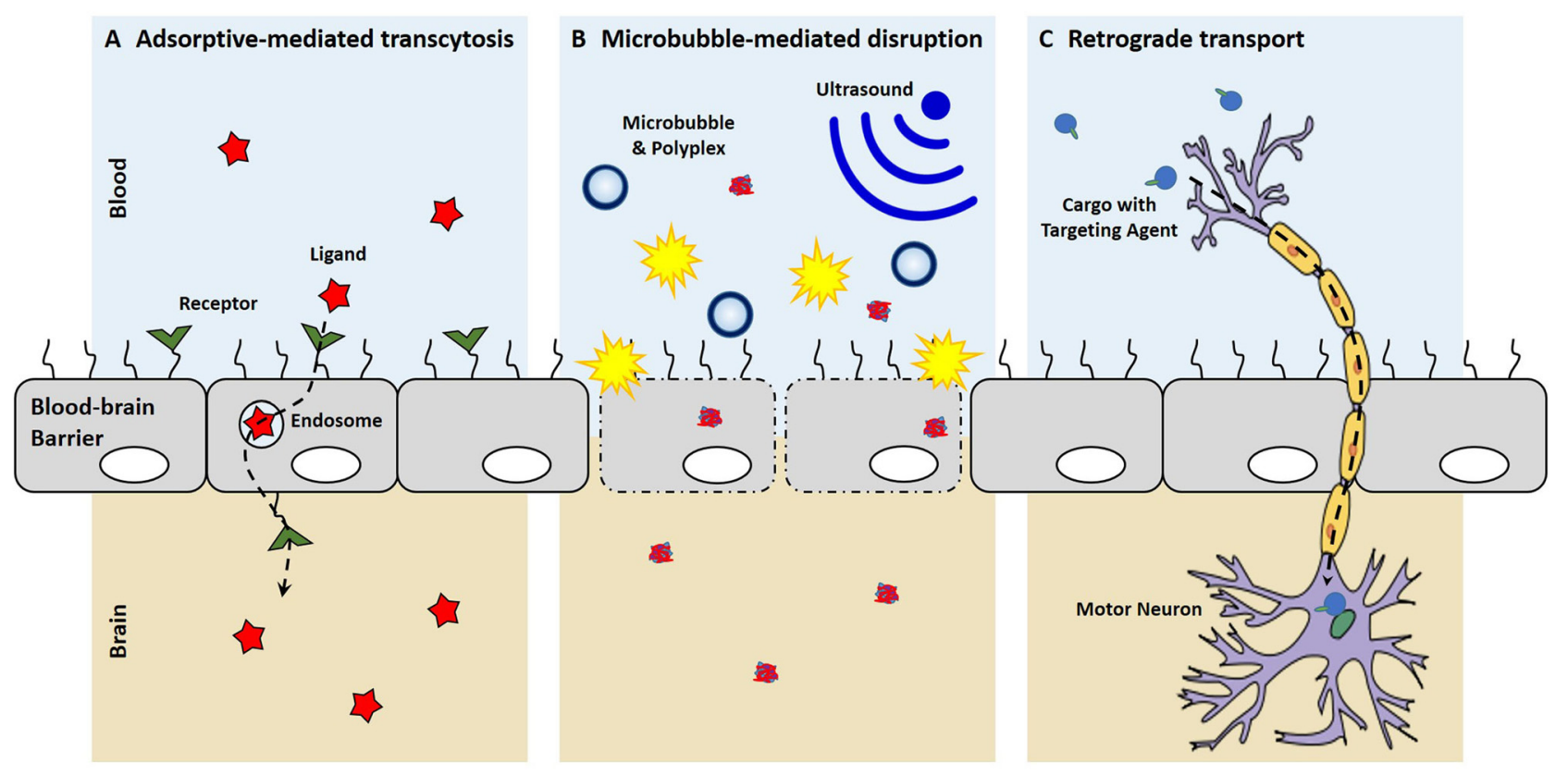

FIGURE 2 | Mechanisms of entering the central nervous system (CNS). (A) With receptor-mediated endocytosis, the binding of a ligand to its receptor on the brain endothelium facilitates cellular endocytosis, vesicular trafficking and eventually exocytosis on the contralateral side into the brain. (B) Microbubble-mediated disruption of the choroid plexus epithelium breaks tight junctions and creates micropores, allowing for the enhanced penetration of polyplexes into the brain. (C) New targeting ligands allow for uptake by peripheral neurons and the retrograde transport of cargo along axons to cell bodies in the CNS.

the brain such as immunoglobulin $\mathrm{G}$ and $70 \mathrm{kDa}$ dextran (Sheikov et al., 2004; Choi et al., 2007, 2010, 2011; Xie et al., 2008). The safety of microbubble-mediated BBB disruption has been evaluated in rats and macaque monkeys with no or limited damage to brain tissue and no behavioral or visual deficits (McDannold et al., 2012; Kobus et al., 2015). Microbubble-mediated disruption of the BBB has been used to increase anti-Huntingtin siRNA delivery into the murine brain to reduce Huntingtin protein levels in animal disease models (Burgess et al., 2012). In another example, DNA can be complexed with cationic polymer-decorated microbubbles to prevent premature degradation. In this manner, microbubble and DNA complexes were used to markedly enhance the expression of brain-derived neurotrophic factor and enhanced green fluorescence protein in murine brains (Huang et al., 2012a,b). Microbubbles can also be co-administered with liposomal gene carriers to specifically open a region of the BBB by focused US, which uses an acoustic lens to center the US at a specific point (Lin et al., 2015). Co-administration of microbubbles with dense PEG-coated nanoparticles was able to open the BBB and transfect a variety of brain cells for at least 28 days with systemic administration (Nance et al., 2014; Mead et al., 2016).

In some cases, such as brain gliomas and traumatic brain injury, there is a natural disruption of the $\mathrm{BBB}$. In small rat brain tumors, there is no $\mathrm{BBB}$ permeability; however, as the tumor grows and neovascularization occurs, ultrastructural defects in the capillary vessels arise causing a stark disruption in the tumor (Yamada et al., 1982). This leaky
$\mathrm{BBB}$ vasculature can be exploited by gene delivery vehicles as a facile method of CNS entry and can greatly complement receptor-mediated transcytosis. PEGylated nanoparticles and liposomes decorated with receptor-mediated transcytosis ligands were able to accumulate in gliomas after systemic administration and delay tumor growth ( $\mathrm{Lu}$ et al., 2006; Yue et al., 2014).

\section{CEREBROSPINAL FLUID INJECTION}

The CSF is produced by the choroid plexus deep in the ventricles and drains along paravenous circulation (Cipolla, 2009). The CNS is unique in that it does not have a traditional lymph system and waste material and metabolites drain from the extracellular space to the CSF (Iliff et al., 2012). While non-viral gene delivery into CSF-filled spaces is not as facile as intravenous administration, it does have the advantages of avoiding systemic circulation and placing therapeutics in close proximity to the brain parenchyma (Johanson et al., 2011). For example, lateral intraventricular injections allow for close proximity to the subventricular zone, a region of the brain containing neural progenitor cells, and may be an appropriate injection site for neurogenesis applications. In addition, there are excellent access points that are used routinely in the clinic including a lumbar puncture or intraventricular cannulas (Belverud et al., 2008; Tobinick, 2016). Substances directly injected into the CSF circumvent the BBB and distribute in the brain depending on size and charge. The ependymal barriers in ventricles are comprised of the choroid plexus cells and in 
the sub-arachnoid space, the arachnoid barrier cells of glia and pial vessels (Abbott et al., 2006). For intraventricular delivery, large molecular weight proteins are not free to diffuse into the brain parenchyma due to the choroid plexus epithelium, which lines the cavities of the ventricles and the cranial and spinal sub-arachnoid space and secretes cerebrospinal fluid (Dohrmann, 1970; Mortazavi et al., 2014). While the ependymal barrier is not as stringent as the BBB, access and penetration into the brain parenchyma are still difficult due to the low diffusion and the constant movement of CSF fluid through the CNS and back into the bloodstream (Pardridge, 2011). While ventricular access of therapeutics to the brain is restricted, delivery to the sub-arachnoid space often results in widespread brain delivery of small molecular weight proteins (Iliff et al., 2012).

\section{Designing Vehicles to Overcome Delivery Barriers}

While the choroid plexus ependymal cell layer acts as a barrier, nucleic acid therapeutics intraventricularly injected are still able to have some efficacy likely due to the direct sampling of neural stem cells into the CSF and some penetration into the parenchyma. Certain formulations of linear PEI were able to diffuse throughout the ventricular space and transfect neurons and glia near the edge (Goula et al., 1998). After intraventricular injection, PEI and DNA complexes have been shown to transfect neural progenitor cells (Lemkine et al., 2002); while PEI complexes decorated with Tet1, a peptide that specifically binds to neuronal cells, bound better to neural progenitor cells and showed an improved transfection of neural progenitors over untargeted complexes (Kwon et al., 2010). Other carrier structures such as liposomes and silica nanoparticles have also been used as nucleic acid delivery vehicles for intraventricular administration. Cationic liposomes and organically modified silica nanoparticles were used to successfully deliver siRNA and plasmid DNA to neuronal cells in vivo, respectively (Bharali et al., 2005; Zou et al., 2010). All of these carriers can help protect nucleic acids as lipoplexes protected mRNA from premature degradation in CSF for up to $4 \mathrm{~h}$ while mRNA alone degraded within 5 min (Anderson et al., 2004). Peptide-decorated micelles filled with dexamethasone, a glucocorticoid that facilitates transport to the nucleus, were able to significantly reduce infarct size after middle cerebral artery occlusion by gene delivery.

Recently, multifunctional gene delivery vehicles have been synthesized with the aim of overcoming many of the barriers to gene delivery such as premature unpackaging, endosomal escape, and DNA release (Table 1). A statistical copolymer of $N$-(2-hydroxypropyl)methacrylate (HPMA), oligo-L-lysine, and melittin was developed for gene delivery after intraventricular injection (Schellinger et al., 2013). The HPMA monomers were for stability, the lysines were developed for DNA condensation and packaging, and the melittin, a membrane-lytic peptide developed from honey bee venom, was included to enhance endosomal escape after vesicular uptake. This polymer efficiently condensed DNA into stable particles to form polyplexes and increased brain transfection about 35 -fold compared to melittin-free analogs. Another polymer designed for in vivo gene delivery utilized a double-headed reversible addition-fragmentation chain transfer agent and a ring-opening polymerization initiator to create two different polymer segments that contribute to different aspects of gene delivery (Wei et al., 2013). This copolymer, PCL-SS$\mathrm{p}$ [(GMA-TEPA)-s-OEGMA], consisted of a block of poly( $\varepsilon$ caprolactone) (PCL) connected by a reducible disulfide to a statistical copolymer of tetraethylenepentamine (TEPA)decorated poly(glycidyl methacrylate) (GMA) and oligo(ethylene glycol) monomethyl ether methacrylate (OEGMA). The TEPA amine groups bind to and condense nucleic acids to form polyplexes while the hydrophobic PCL and hydrophilic OEGMA provide extracellular stability. After polyplex internalization, the amine groups contribute to endosomal escape by $\mathrm{pH}$ buffering and the internal disulfide bond can be reduced by cytosolic glutathione facilitating polyplex destabilization and nucleic acid release. These polyplexes were shown to have diameters less than $200 \mathrm{~nm}$, transfected HeLa cells more efficiently than PEI in vitro, and delivered luciferase genes to the brain more efficiently than its individual components. To improve transfection further, the amines of this polymer were guanidinylated and investigated in vivo. The delocalized charge of guanidinium groups is attributed to stronger interaction with DNA than amines and greater cell internalization by interacting with cell surface phosphates and sulfates (Wehling et al., 1975; Cheng et al., 2013). While guanidinium groups show improved transfection in vitro, they did not translate to augmented transfection in vivo likely due to premature unpackaging as guanidinium groups have a predilection for sulfates of heparan sulfate proteoglycans over nucleic acid phosphate groups (Choi et al., 2015). Recently, we developed a new endosomal-escaping, polymeric vehicle that has a triggered exposure of a membrane lytic peptide when in the acidic pH of endosomes (Cheng et al., 2016). This polymer, called Virus-Inspired Polymer for Endosomal Release (VIPER), is composed of a cationic block, poly(OEGMA)-co-poly(2(dimethylamino)ethyl methacrylate) (p(OEGMA-DMAEMA)), for nucleic acid condensation and a $\mathrm{pH}$-sensitive block, poly(2diisopropylaminoethyl methacrylate)-co-poly(pyridyl disulfide ethyl methacrylate) (p(DIPAMA-PDSEMA)), for triggered display of a membrane lytic peptide, melittin, in acidic conditions. VIPER polyplexes, or polymer-DNA complexes, showed membrane-lytic activity only in the acidic conditions of the cell endosome and efficient gene transfer to a variety of cell types and therefore may be useful for CNS gene transfer.

Cerebrospinal fluid injections into other areas of the CNS have also been employed for the administration of nucleic acid carriers. After injection into the cisterna magma of rats, liposomes delivered luciferase plasmid throughout the brain that was still detectable 7-10 days later (Hauck et al., 2008). Interestingly, when the same system was directly injected into the parenchyma, luciferase expression was not as distributed. A micelle system of PEG-aspartic acid polymer was able to provide sustained protein expression with minimal immunogenicity 
(Uchida et al., 2013). Nucleic acid administration into the lumbar subarachnoid space has also been accomplished with a variety of delivery vehicles. Poly(lactic-co-glycolic acid) microparticles containing plasmid DNA that encodes IL-10 were able to relieve neuropathic pain in rats for greater than 74 days (Soderquist et al., 2010). PEI complexes decorated with a peptide from nerve growth factor were able to more specifically transfect dorsal root ganglia (Zeng et al., 2007). By creating Tat decorated-PEI complexes with magnetic iron beads, researchers were able to use magnetic fields to direct the movement of DNA complexes into remote areas away from the injection site in rat spinal cords (Song et al., 2010). While sufficient levels of gene transfection are achieved after CSF injection, the choroid plexus epithelium still prevents most of the vehicles from entering the parenchyma which results in a significant loss of transfection potential.

\section{Choroid Plexus Epithelium Disruption}

In a similar fashion to BBB disruption, the choroid plexus epithelium may be transiently disrupted by microbubbles and ultrasound to allow for the enhanced penetration of materials into the brain parenchyma from the CSF fluid. Custom microbubbles were prepared and did not aggregate with aforementioned PCL-SS-p[(GMATEPA)-s-OEGMA] polyplexes (Tan et al., 2016). In in vitro transwell assays, these microbubbles were able to sonoporate immortalized choroid plexus monolayers to allow for the enhanced flow through of $5 \mathrm{kDa}$ PEG and $70 \mathrm{kDa}$ dextran. Upon in vivo administration into murine ventricles, the microbubbles and ultrasound were able to significantly increase polyplex transfection of cells with luciferase compared to polyplexes alone or polyplexes and microbubbles without ultrasound. Temporary microbubble-mediated disruption of the choroid plexus epithelium seems like a viable strategy to enhance the penetration of polyplexes and may garner more research in the future.

\section{INTRAPARENCHYMAL INJECTION}

Intraparenchymal injection is the most direct access to discrete anatomy and cells of the brain and spinal cord. However, there are several critical challenges notwithstanding the inherent risk of an invasive CNS injection. Injection or probe placement alone can create a reactive gliosis that may limit the transport of a therapeutic or exacerbate the disease (Polikov et al., 2005; Potts et al., 2013). Methods for convection enhanced delivery and the use of small caliber pipettes can mitigate some of these concerns and allow targeted delivery of relatively large volumes without harm (Mano et al., 2016). Once in the parenchyma, therapeutics have variable degrees of diffusion and entrapment that can be modeled based on protein or drug size and composition (Patlak et al., 1983; Ghersi-Egea et al., 2002; Hrabe et al., 2004; Nicholson et al., 2011). After parenchymal diffusion, clearance is regulated by the lymphatic system which is comprised of the glia cells that ensheath the venous system of the brain which is localized primarily near the dural surfaces (Iliff et al., 2012; Louveau et al., 2015). In general, small molecular weight substances are able to diffuse readily and are cleared in minutes. Larger molecular weight substances may either lack significant diffusion or be cleared over a course of hours (Syková and Nicholson, 2008).

\section{Bolus Injection}

While the location of intraparenchymal injections into the brain can vary, the same type of nucleic acid delivery vehicles is still utilized. PEI decorated with $2 \mathrm{kDa}$ PEG chains resulted in improved gene delivery after intrathecal administration into the lumber spinal cord subarachnoid space compared to PEI (Tang et al., 2003). Reducible arginine-PAMAM dendrimers were able to knockdown genes after injection into the cortex (Kim et al., 2010). Biodegradable poly( $\beta$-amino esters) that were lyophilized and stored for over 2 years effectively transfected brain glioblastomas, demonstrating long-term storage and efficacy for clinical translation (Guerrero-Cázares et al., 2014). Reversibly conjugated siRNA to liposomes was able to efficiently silence genes in oligodendrocytes after administration into the corpus callosum (Chen et al., 2010). Liposomes encapsulating siRNA have also shown effective gene knockdown of the GluN1 subunit of NMDA receptors in neurons (Rungta et al., 2013). Targeting agents have also been used to enhance the nucleic acid delivery vehicles. PEGylated PEI was targeted with folate, which binds to folate receptor often overexpressed on cancer cells, and liposomes were targeted with transferrin to improve the delivery of plasmids and siRNA after injection into the right striatum (Cardoso et al., 2008; Liang et al., 2009).

\section{Sustained Delivery}

The compact and tortuous morphology of the brain parenchyma severely limits the diffusion of nucleic acid delivery vehicles away from the administration site. To overcome this, sustained delivery is utilized to constantly introduce more vehicles and increase the diffusion throughout the brain. In one example, an osmotic pump was able to continually inject siRNA and liposome complexes into the frontal lobe to knockdown the resistance of gliomas to therapy (Kato et al., 2010). This treatment significantly sensitized tumors to the chemotherapeutic agents and extended the survival of mice. In other cases, a cannula is implanted in the brain for acute direct injections or chronic administration. Repeated dosing of siRNA against toxic Huntingtin protein in $\beta$-cyclodextin carriers was able to alleviate motor deficits in a Huntington's disease mouse model (Godinho et al., 2013).

Like the osmotic pump, convection-enhanced delivery is administered intraparenchymally and used to continually introduce therapeutics. A cannula is typically inserted stereotaxically into a designated spot in the brain and a therapeutic fluid is continuously injected under positive pressure (Allard et al., 2009). The administration of siRNA by convection-enhanced delivery was able to silence genes in oligodendrocytes (Querbes et al., 2009) and silence Huntingtin gene in a widespread manner across the brain (Stiles et al., 
2012). When a cell-penetrating peptide, TAT, was attached to liposomes, gene transfection increased in vivo; however, expression was restricted to the vicinity of the infusion catheter (MacKay et al., 2008). When comparing positively and negatively charged liposomes, anionic liposomes were better able to spread throughout the brain parenchyma with similar transfection levels (Kenny et al., 2013).

\section{RETROGRADE TRANSPORT}

While there have been substantial advances in brain-targeted delivery to treat diseases that affect specific parts of the brain like Alzheimer's Disease (Kumar et al., 2007; Spencer and Verma, 2007; Yu et al., 2011), few therapeutic options are available for degenerative diseases that affect motor neurons because many of the potential genes and siRNA drugs show limited diffusion and penetration to motor neurons deep in the CNS parenchyma (Monani, 2005; Mitchell and Borasio, 2007). For decades, classes of viruses have been known to infect neuronal projections in the periphery and undergo retrograde axonal transport into the brain and spinal cord (LaVail and LaVail, 1972; Salinas et al., 2010). Thus, several lab have begun to systematically mutate adeno-associated vectors in order to expand their clinical application and increase delivery into the CNS (Maheshri et al., 2006; Kotterman and Schaffer, 2014), innovative strategies have been adopted to utilize retrograde axonal transport to deliver biologics into the spinal cord (Xu et al., 2005; Hollis et al., 2008; Snyder et al., 2011). As a result, these viruses have been engineered and shown to be effective for remote gene transfer into the CNS after intramuscular injection to induce neurotrophic factor expression in animal models of neurodegenerative disease (Kaspar et al., 2003; Azzouz et al., 2004; Petruska et al., 2010; Benkhelifa-Ziyyat et al., 2013; Hirano et al., 2013).

Recently, small targeting agents have been used to direct the trafficking of cargo into the CNS after peripheral administration (Figure 2). Tetanus toxin subunit-C (TTC), an atoxic fragment of tetanus toxin that contains the ganglioside-binding site, is able to mediate uptake at both pre- and post-synaptic at nerve termini to allow retrograde transport passage of TTC within neurons (Price et al., 1975; Schwab et al., 1979). Consequently, these trans-synaptic properties of TTC have been exploited as a fusion protein to enable delivery into the spinal cord after TTC uptake at peripheral nerve termini (Francis et al., 2004; Chian et al., 2009; Li et al., 2009). While the TTC fusion-proteins were shown to increase delivery into the spinal cord, these studies were not able to discern a therapeutic benefit, which may suggest that that TTC-fusions do not escape the endosome after uptake and remain sequestered in the vescicle that mediated uptake. More recently, a targeted axonal import peptide (TAxI) was identified by in vivo phage display. The TAxI peptide was able to mediate uptake and delivery of an active Cre recombinase into the nucleus of spinal cord motor neurons after hind limb intramuscular injection (Sellers et al., 2016). These data suggest that small peptides are not only able to mediate synaptic uptake at nerve termini and retrograde transport within neurons, but they allow for functional protein cargo delivery via the neuron. While there have yet to be any reports of synthetic, retrograde nucleic acid delivery into the CNS, the discovery of targeting ligands that mediate uptake by neurons in the periphery, transport within neurons to the CNS, and release of active cargo into the cytoplasm has the potential of opening a whole new delivery route for non-viral technologies to target motor neurons for gene delivery.

Another route of administration that takes advantage of retrograde transport through neurons is intranasal administration. After introduction into the nasal cavity, molecules are believed to travel along olfactory nerve pathways and end up in the brain parenchyma and CSF by bypassing the BBB (Patel et al., 2009). Peptides, proteins, and small molecules have shown to be able to be delivered into the CNS after intranasal administration. While this route is non-invasive, the nasal cavity has many barriers including enzymes and mucous; furthermore, compounds similar to those that have shown CNS delivery have reportedly not entered the CNS after intranasal administration (Dhuria et al., 2010). The formulation and method of delivery may affect retrograde transport as well as other experimental factors such as head position, volume, $\mathrm{pH}$ and osmolarity (Dhuria et al., 2010). Plasmid DNA ranging from $3.5 \mathrm{~kb}$ to $14.2 \mathrm{~kb}$ were able to show absorption and brain distribution after intranasal administration (Han et al., 2007). Intranasal delivery of an telomerase-inhibiting oligonucleotide was able to prolong the survival of human tumor-bearing rats by over 30 days (Hashizume et al., 2008). Carriers for intranasal gene delivery follow the same principles as other vehicles administered by other routes. Polymeric vehicles comprised of methoxy PEG, poly $(\varepsilon$-caprolactone $)$ and TAT peptide demonstrated better delivery of siRNA to the brain than naked siRNA or carrier-mediated intravenous delivery (Kanazawa et al., 2013).

\section{CONCLUSION}

While viral vectors are still the main type of vehicles used in clinical trials, non-viral vectors are gaining traction due to their potential safety advantages, greater customization, ease of manufacturing and ability to deliver all nucleic acid varieties (Niidome and Huang, 2002; Thomas et al., 2003). The ability of viral vectors to permanently alter the genome and activate the immune system make non-viral vectors more compelling for clinical trials. However, the lower efficacy and transfection levels by synthetic vectors hinder their wide clinical use. For any application, nucleic acid delivery vehicles face cellular obstacles such as recognition by pertinent cells, internalization into cells, escaping the lysosomal degradation pathway and unpackaging the nucleic acids in the cell cytosol. Delivery into the CNS presents an even greater challenge due to the supracellular BBB and BSCB. An apropos administration route must be chosen to maximize therapeutics at the treatment site (i.e., direct injections); however, caution must be heeded in avoiding unnecessary damage to healthy tissues by direct administration into the CNS (i.e., intravenous and peripheral administration). Each 
route of administration has its advantages and disadvantages, as well as local barriers, as previously discussed. Fortunately, the advances in vehicular design, materials and synthesis described above have allowed for specific engineering of gene delivery vehicles to overcome these challenges and step closer to the transfection efficiency of viruses. Improvements such as nucleic acid shielding and targeting have lessened premature degradation and increased the localization of cargo in the CNS. Advances in crossing the BBB and sustained delivery directly into the brain allow for improved gene transfection and a step closer to clinical application. Meanwhile, new techniques such as microbubble-mediated sonoporation and small molecule-mediated retrograde transport allow the permeation of otherwise excluded vehicles into the brain and spinal cord. All of these examples can serve as guidelines and inspiration for the next generation of synthetic gene delivery vectors. With these improvements, we anticipate that synthetic delivery systems will be applied more successfully for nucleic

\section{REFERENCES}

Abbott, N. J., Rönnbäck, L., and Hansson, E. (2006). Astrocyte-endothelial interactions at the blood-brain barrier. Nat. Rev. Neurosci. 7, 41-53. doi: 10. 1038/nrn1824

Abdelhady, H. G., Allen, S., Davies, M. C., Roberts, C. J., Tendler, S. J. B., and Williams, P. M. (2003). Direct real-time molecular scale visualisation of the degradation of condensed DNA complexes exposed to DNase 1. Nucleic Acids Res. 31, 4001-4005. doi: 10.1093/nar/gkg462

Al-Dosari, M. S., and Gao, X. (2009). Nonviral gene delivery: principle, limitations and recent progress. AAPS J. 11, 671-681. doi: 10.1208/s12248-0099143-y

Allard, E., Passirani, C., and Benoit, J.-P. (2009). Convection-enhanced delivery of nanocarriers for the treatment of brain tumors. Biomaterials 30, 2302-2318. doi: 10.1016/j.biomaterials.2009.01.003

Alvarez-Erviti, L., Seow, Y., Yin, H., Betts, C., Lakhal, S., and Wood, M. J. A. (2011). Delivery of siRNA to the mouse brain by systemic injection of targeted exosomes. Nat. Biotechnol. 29, 341-345. doi: 10.1038/nbt.1807

Anderson, D. M., Hall, L. L., Ayyalapu, A. R., Irion, V. R., Nantz, M. H., and Hecker, J. G. (2004). Stability of mRNA/cationic lipid lipoplexes in human and rat cerebrospinal fluid: methods and evidence for nonviral mRNA gene delivery to the central nervous system. Hum. Gene Ther. 14, 191-202. doi: 10. 1089/10430340360535751

Azzouz, M., Ralph, G. S., Storkebaum, E., Walmsley, L. E., Mitrophanous, K. A., Kingsman, S. M., et al. (2004). VEGF delivery with retrogradely transported lentivector prolongs survival in a mouse ALS model. Nature 429, 413-417. doi: 10.1038/nature02544

Banks, W. A. (2016). From blood-brain barrier to blood-brain interface: new opportunities for CNS drug delivery. Nat. Rev. Drug Discov. 15, 275-292. doi: $10.1038 / \mathrm{nrd} .2015 .21$

Barchet, T. M., and Amiji, M. M. (2009). Challenges and opportunities in CNS delivery of therapeutics for neurodegenerative diseases. Expert Opin. Drug Deliv. 6, 211-225. doi: 10.1517/17425240902758188

Begley, D. (2003). Understanding and circumventing the blood-brain barrier. Acta Paediatr. Suppl. 443, 83-91. doi: 10.1111/j.1651-2227.2003. tb00226.x

Belverud, S., Mogilner, A., and Schulder, M. (2008). Intrathecal pumps. Neurotherapeutics 5, 114-122. doi: 10.1016/j.nurt.2007.10.070

Benkhelifa-Ziyyat, S., Besse, A., Roda, M., Duque, S., Astord, S., Carcenac, R., et al. (2013). Intramuscular scAAV9-SMN injection mediates widespread gene delivery to the spinal cord and decreases disease severity in SMA mice. Mol. Ther. 21, 282-290. doi: 10.1038/mt.2012.261

Bharali, D. J., Klejbor, I., Stachowiak, E. K., Dutta, P., Roy, I., Kaur, N., et al. (2005). Organically modified silica nanoparticles: a nonviral vector for in vivo acid therapies in animal models of CNS disease and will make significant progress toward clinical evaluation in the upcoming years.

\section{AUTHOR CONTRIBUTIONS}

J-KYT: led conception, writing of review, drafting and editing figures. SHP and PJH: conceived, assisted in writing and editing topic. BP and DLS: assisted in writing and editing topic.

\section{ACKNOWLEDGMENTS}

This work was supported by NIH 2R01NS064404 (SHP \& PJH), Congressionally Directed Medical Research Programs DOD W81XWH-14-1-0586 (PJH \& SHP). J-KYT was supported by National Science Foundation (NSF) GRFP (2011128558); Binhan Pham was supported by Mary Gates Undergraduate Research Fellowship.

gene delivery and expression in the brain. Proc. Natl. Acad. Sci. U S A 102 11539-11544. doi: 10.1073/pnas.0504926102

Burgess, A., Huang, Y., Querbes, W., Sah, D. W., and Hynynen, K. (2012). Focused ultrasound for targeted delivery of siRNA and efficient knockdown of Htt expression. J. Control. Release 163, 125-129. doi: 10.1016/j.jconrel.2012.08.012

Burke, P. A., Pun, S. H., and Reineke, T. M. (2013). Advancing polymeric delivery systems amidst a nucleic acid therapy renaissance. ACS Macro Lett. 2, 928-934. doi: $10.1021 / \mathrm{mz} 400418 \mathrm{j}$

Cardoso, A. L. C., Simões, S., de Almeida, L. P., Plesnila, N., Pedroso de Lima, M. C., Wagner, E., et al. (2008). Tf-lipoplexes for neuronal siRNA delivery: a promising system to mediate gene silencing in the CNS. J. Control. Release 132, 113-123. doi: 10.1016/j.jconrel.2008.08.014

Chen, Q., Butler, D., Querbes, W., Pandey, R. K., Ge, P., Maier, M. A., et al. (2010). Lipophilic siRNAs mediate efficient gene silencing in oligodendrocytes with direct CNS delivery. J. Control. Release 144, 227-232. doi: 10.1016/j.jconrel. 2010.02.011

Cheng, Q., Huang, Y., Zheng, H., Wei, T., Zheng, S., Huo, S., et al. (2013). The effect of guanidinylation of PEGylated poly(2-aminoethyl methacrylate) on the systemic delivery of siRNA. Biomaterials 34, 3120-3131. doi: 10.1016/j. biomaterials.2013.01.043

Cheng, Y., Yumul, R. C., and Pun, S. H. (2016). Virus-inspired polymer for efficient in vitro and in vivo gene delivery. Angew. Chem. Int. Ed Engl. 55, 12013-12017. doi: 10.1002/anie.201605958

Chian, R.-J. J., Li, J., Ay, I., Celia, S. A., Kashi, B. B., Tamrazian, E., et al. (2009). IGF-1: tetanus toxin fragment $\mathrm{C}$ fusion protein improves delivery of IGF-1 to spinal cord but fails to prolong survival of ALS mice. Brain Res. 1287, 1-19. doi: 10.1016/j.brainres.2009.06.066

Choi, J. J., Pernot, M., Small, S. A., and Konofagou, E. E. (2007). Noninvasive, transcranial and localized opening of the blood-brain barrier using focused ultrasound in mice. Ultrasound Med. Biol. 33, 95-104. doi: 10.1016/j. ultrasmedbio.2006.07.018

Choi, J. J., Selert, K., Gao, Z., Samiotaki, G., Baseri, B., and Konofagou, E. E. (2011). Noninvasive and localized blood-brain barrier disruption using focused ultrasound can be achieved at short pulse lengths and low pulse repetition frequencies. J. Cereb. Blood Flow Metab. 31, 725-737. doi: 10.1038/jcbfm.2010. 155

Choi, J. L., Tan, J. Y., Sellers, D. L., Wei, H., Horner, P. J., and Pun, S. H. (2015). Guanidinylated block copolymers for gene transfer: a comparison with amine-based materials for in vitro and in vivo gene transfer efficiency. Biomaterials 54, 87-96. doi: 10.1016/j.biomaterials.2015.03.008

Choi, J. J., Wang, S., Tung, Y.-S., Morrison, B. III., and Konofagou, E. E. (2010). Molecules of various pharmacologically-relevant sizes can cross the ultrasound-induced blood-brain barrier opening in vivo. Ultrasound Med. Biol. 36, 58-67. doi: 10.1016/j.ultrasmedbio.2009.08.006 
Cipolla, M. J. (2009). "Colloquium series on integrated systems physiology: from molecule to function," in The Cerebral Circulation, eds D. N. Granger and J. Granger (Williston, VT: Morgan \& Claypool life Sciences), 1-69.

Costa, P. M., Cardoso, A. L., Mendonça, L. S., Serani, A., Custódia, C., Conceição, M., et al. (2013). Tumor-targeted chlorotoxin-coupled nanoparticles for nucleic acid delivery to glioblastoma cells: a promising system for glioblastoma treatment. Mol. Ther. Nucleic Acids 2:e100. doi: 10. 1038/mtna.2013.30

Dhuria, S. V., Hanson, L. R., and Frey, W. H. I. II. (2010). Intranasal delivery to the central nervous system: mechanisms and experimental considerations. J. Pharm. Sci. 99, 1654-1673. doi: 10.1002/jps.21924

Dodge, J. C., Treleaven, C. M., Fidler, J. A., Hester, M., Haidet, A., Handy, C., et al. (2010). AAV4-mediated expression of IGF-1 and VEGF within cellular components of the ventricular system improves survival outcome in familial ALS mice. Mol. Ther. 18, 2075-2084. doi: 10.1038/mt.2010.206

Dohrmann, G. J. (1970). The choroid plexus: a historical review. Brain Res. 18, 197-218. doi: 10.1016/0006-8993(70)90324-0

Emlen, W., and Mannik, M. (1984). Effect of DNA size and strandedness on the in vivo clearance and organ localization of DNA. Clin. Exp. Immunol. 56, $185-192$.

Francis, J. W., Figueiredo, D., vanderSpek, J. C., Ayala, L. M., Kim, Y. S., Remington, M. P., et al. (2004). A survival motor neuron:tetanus toxin fragment $\mathrm{C}$ fusion protein for the targeted delivery of SMN protein to neurons. Brain Res. 995, 84-96. doi: 10.1016/j.brainres.2003.09.063

Gabathuler, R. (2010). Development of new peptide vectors for the transport of therapeutic across the blood-brain barrier. Ther. Deliv. 1, 571-586. doi: 10. $4155 /$ tde. 10.35

Gao, Y., Wang, Z.-Y., Zhang, J., Zhang, Y., Huo, H., Wang, T., et al. (2014). RVG-peptide-linked trimethylated chitosan for delivery of siRNA to the brain. Biomacromolecules 15, 1010-1018. doi: 10.1021/bm401906p

Ghersi-Egea, J.-F., Gorevic, P. D., Ghiso, J., Frangione, B., Patlak, C. S., and Fenstermacher, J. D. (2002). Fate of cerebrospinal fluid-borne amyloid $\beta$-peptide: rapid clearance into blood and appreciable accumulation by cerebral arteries. J. Neurochem. 67, 880-883. doi: 10.1046/j.1471-4159.1996. 67020880.x

Godinho, B. M. D. C., Ogier, J. R., Darcy, R., O’Driscoll, C. M., and Cryan, J. F. (2013). Self-assembling modified $\beta$-cyclodextrin nanoparticles as neuronal siRNA delivery vectors: focus on Huntington's disease. Mol. Pharm. 10, 640-649. doi: 10.1021/mp3003946

Goula, D., Remy, J. S., Erbacher, P., Wasowicz, M., Levi, G., Abdallah, B., et al. (1998). Size, diffusibility and transfection performance of linear PEI/DNA complexes in the mouse central nervous system. Gene Ther. 5, 712-717. doi: 10. 1038/sj.gt.3300635

Greenleaf, W. J., Bolander, M. E., Sarkar, G., Goldring, M. B., and Greenleaf, J. F. (1998). Artificial cavitation nuclei significantly enhance acoustically induced cell transfection. Ultrasound Med. Biol. 24, 587-595. doi: 10.1016/s03015629(98)00003-9

Guerrero-Cázares, H., Tzeng, S. Y., Young, N. P., Abutaleb, A. O., QuiñonesHinojosa, A., and Green, J. J. (2014). Biodegradable polymeric nanoparticles show high efficacy and specificity at DNA delivery to human glioblastoma in vitro and in vivo. ACS Nano 8, 5141-5153. doi: 10.1021/nn501197v

Han, I. K., Kim, M. Y., Byun, H. M., Hwang, T. S., Kim, J. M., Hwang, K. W., et al. (2007). Enhanced brain targeting efficiency of intranasally administered plasmid DNA: an alternative route for brain gene therapy. J. Mol. Med. (Berl.) 85, 75-83. doi: 10.1007/s00109-006-0114-9

Hanz, S., and Fainzilber, M. (2004). Integration of retrograde axonal and nuclear transport mechanisms in neurons: implications for therapeutics. Neuroscientist 10, 404-408. doi: 10.1177/1073858404267884

Hashizume, R., Ozawa, T., Gryaznov, S. M., Bollen, A. W., Lamborn, K. R., Frey, W. H., et al. (2008). New therapeutic approach for brain tumors: intranasal delivery of telomerase inhibitor GRN163. Neuro. Oncol. 10, 112-120. doi: $10.1215 / 15228517-2007-052$

Hauck, E. S., Zou, S., Scarfo, K., Nantz, M. H., and Hecker, J. G. (2008). Whole animal in vivo imaging after transient, nonviral gene delivery to the rat central nervous system. Mol. Ther. 16, 1857-1864. doi: 10.1038/mt.2008.183

Hervé, F., Ghinea, N., and Scherrmann, J.-M. (2008). CNS delivery via adsorptive transcytosis. AAPS J. 10, 455-472. doi: 10.1208/s12248-008-9055-2

Hirano, M., Kato, S., Kobayashi, K., Okada, T., Yaginuma, H., and Kobayashi, K. (2013). Highly efficient retrograde gene transfer into motor neurons by a lentiviral vector pseudotyped with fusion glycoprotein. PLoS One 8:e75896. doi: 10.1371/journal.pone.0075896

Hollis, E. R. II., Kadoya, K., Hirsch, M., Samulski, R. J., and Tuszynski, M. H. (2008). Efficient retrograde neuronal transduction utilizing self-complementary AAV1. Mol. Ther. 16, 296-301. doi: 10.1038/sj.mt.6300367

Hrabe, J., Hrabětová, S., and Segeth, K. (2004). A model of effective diffusion and tortuosity in the extracellular space of the brain. Biophys. J. 87, 1606-1617. doi: 10.1529/biophysj.103.039495

Huang, Q., Deng, J., Wang, F., Chen, S., Liu, Y., Wang, Z., et al. (2012a). Targeted gene delivery to the mouse brain by MRI-guided focused ultrasound-induced blood-brain barrier disruption. Exp. Neurol. 233, 350-356. doi: 10.1016/j. expneurol.2011.10.027

Huang, Q., Deng, J., Xie, Z., Wang, F., Chen, S., Lei, B., et al. (2012b). Effective gene transfer into central nervous system following ultrasoundmicrobubbles-induced opening of the blood-brain barrier. Ultrasound Med. Biol. 38, 1234-1243. doi: 10.1016/j.ultrasmedbio.2012.02.019

Huang, R., Ke, W., Han, L., Liu, Y., Shao, K., Jiang, C., et al. (2010). Lactoferrinmodified nanoparticles could mediate efficient gene delivery to the brain in vivo. Brain Res. Bull. 81, 600-604. doi: 10.1016/j.brainresbull.2009.12.008

Huang, R., Ke, W., Liu, Y., Jiang, C., and Pei, Y. (2008). The use of lactoferrin as a ligand for targeting the polyamidoamine-based gene delivery system to the brain. Biomaterials 29, 238-246. doi: 10.1016/j.biomaterials.2007.09.024

Huang, R.-Q., Qu, Y.-H., Ke, W.-L., Zhu, J.-H., Pei, Y.-Y., and Jiang, C. (2007). Efficient gene delivery targeted to the brain using a transferrin-conjugated polyethyleneglycol-modified polyamidoamine dendrimer. FASEB J. 21, 1117-1125. doi: 10.1096/fj.06-7380com

Hwang, D. W., Son, S., Jang, J., Youn, H., Lee, S., Lee, D., et al. (2011). A brain-targeted rabies virus glycoprotein-disulfide linked PEI nanocarrier for delivery of neurogenic microRNA. Biomaterials 32, 4968-4975. doi: 10.1016/j. biomaterials.2011.03.047

Iliff, J. J., Wang, M., Liao, Y., Plogg, B. A., Peng, W., Gundersen, G. A., et al. (2012). A paravascular pathway facilitates CSF flow through the brain parenchyma and the clearance of interstitial solutes, including amyloid $\beta$. Sci. Transl. Med. 4:147ra111. doi: 10.3410/f.717953972.793459499

Iliff, J. J., Wang, M., Zeppenfeld, D. M., Venkataraman, A., Plog, B. A., Liao, Y., et al. (2013). Cerebral arterial pulsation drives paravascular CSF-interstitial fluid exchange in the murine brain. J. Neurosci. 33, 18190-18199. doi: 10. 1523/JNEUROSCI.1592-13.2013

Immordino, L., Dosio, F., and Cattel, L. (2006). Stealth liposomes: review of the basic science, rationale and clinical applications. Int. J. Nanomedicine 1, 297-315.

Johanson, C. E., Stopa, E. G., and McMillan, P. N. (2011). The blood-cerebrospinal fluid barrier: structure and functional significance. Methods Mol. Biol. 686, 101-131. doi: 10.1007/978-1-60761-938-3_4

Kanazawa, T., Akiyama, F., Kakizaki, S., Takashima, Y., and Seta, Y. (2013). Delivery of siRNA to the brain using a combination of nose-to-brain delivery and cell-penetrating peptide-modified nano-micelles. Biomaterials 34, 9220-9226. doi: 10.1016/j.biomaterials.2013.08.036

Kaspar, B. K., Lladó, J., Sherkat, N., Rothstein, J. D., and Gage, F. H. (2003), Retrograde viral delivery of IGF-1 prolongs survival in a mouse ALS model. Science 301, 839-842. doi: 10.1126/science.1086137

Kato, T., Natsume, A., Toda, H., Iwamizu, H., Sugita, T., Hachisu, R., et al. (2010). Efficient delivery of liposome-mediated MGMT-siRNA reinforces the cytotoxity of temozolomide in GBM-initiating cells. Gene Ther. 17, 1363-1371. doi: $10.1038 /$ gt. 2010.88

Kawabata, K., Takakura, Y., and Hashida, M. (1995). The fate of plasmid DNA after intravenous injection in mice: involvement of scavenger receptors in its hepatic uptake. Pharm. Res. 12, 825-830. doi: 10.1023/A:1016248701505

Ke, W., Shao, K., Huang, R., Han, L., Liu, Y., Li, J., et al. (2009). Gene delivery targeted to the brain using an Angiopep-conjugated polyethyleneglycolmodified polyamidoamine dendrimer. Biomaterials 30, 6976-6985. doi: 10. 1016/j.biomaterials.2009.08.049

Kenny, G. D., Bienemann, A. S., Tagalakis, A. D., Pugh, J. A., Welser, K., Campbell, F., et al. (2013). Multifunctional receptor-targeted nanocomplexes for the delivery of therapeutic nucleic acids to the brain. Biomaterials 34, 9190-9200. doi: 10.1016/j.biomaterials.2013.07.081

Kim, I. D., Lim, C. M., Kim, J. B., Nam, H. Y., Nam, K., Kim, S. W., et al. (2010). Neuroprotection by biodegradable PAMAM ester (e-PAM-R)mediated HMGB1 siRNA delivery in primary cortical cultures and in the 
postischemic brain. J. Control. Release 142, 422-430. doi: 10.1016/j.jconrel. 2009.11.011

Ko, Y. T., Bhattacharya, R., and Bickel, U. (2009). Liposome encapsulated polyethylenimine/ODN polyplexes for brain targeting. J. Control. Release 133, 230-237. doi: 10.1016/j.jconrel.2008.10.013

Kobus, T., Vykhodtseva, N., Pilatou, M., Zhang, Y., and McDannold, N. (2015). Safety validation of repeated blood-brain barrier disruption using focused ultrasound. Ultrasound Med. Biol. 42, 481-492. doi: 10.1016/j.ultrasmedbio. 2015.10.009

Kotterman, M. A., and Schaffer, D. V. (2014). Engineering adeno-associated viruses for clinical gene therapy. Nat. Rev. Genet. 15, 445-451. doi: 10. $1038 / \mathrm{nrg} 3742$

Kumar, P., Wu, H., McBride, J. L., Jung, K.-E., Kim, M. H., Davidson, B. L., et al. (2007). Transvascular delivery of small interfering RNA to the central nervous system. Nature 448, 39-43. doi: 10.1038/nature05901

Kwon, E. J., Lasiene, J., Jacobson, B. E., Park, I.-K., Horner, P. J., and Pun, S. H. (2010). Targeted nonviral delivery vehicles to neural progenitor cells in the mouse subventricular zone. Biomaterials 31, 2417-2424. doi: 10.1016/j. biomaterials.2009.11.086

Laga, R., Carlisle, R., Tangney, M., Ulbrich, K., and Seymour, L. W. (2012). Polymer coatings for delivery of nucleic acid therapeutics. J. Control. Release 161, 537-553. doi: 10.1016/j.jconrel.2012.02.013

LaVail, J. H., and LaVail, M. M. (1972). Retrograde axonal transport in the central nervous system. Science 176, 1416-1417. doi: 10.1126/science.176.4042.1416

Lemkine, G. F., Mantero, S., Migné, C., Raji, A., Goula, D., Normandie, P., et al. (2002). Preferential transfection of adult mouse neural stem cells and their immediate progeny in vivo with polyethylenimine. Mol. Cell. Neurosci. 19, 165-174. doi: 10.1006/mcne.2001.1084

Li, J., Chian, R. J., Ay, I., Kashi, B. B., Celia, S. A., Tamrazian, E., et al. (2009). Insect GDNF:TTC fusion protein improves delivery of GDNF to mouse CNS. Biochem. Biophys. Res. Commun. 390, 947-951. doi: 10.1016/j.bbrc.2009.10.083

Liang, B., He, M.-L., Chan, C.-Y., Chen, Y.-C., Li, X.-P., Li, Y., et al. (2009). The use of folate-PEG-grafted-hybranched-PEI nonviral vector for the inhibition of glioma growth in the rat. Biomaterials 30, 4014-4020. doi: 10.1016/j. biomaterials.2009.04.011

Lin, C. Y., Hsieh, H. Y., Pitt, W. G., Huang, C. Y., Tseng, I. C., Yeh, C. K., et al. (2015). Focused ultrasound-induced blood-brain barrier opening for non-viral, non-invasive and targeted gene delivery. J. Control. Release 212, 1-9. doi: 10. 1016/j.jconrel.2015.06.010

Liu, Y., Huang, R., Han, L., Ke, W., Shao, K., Ye, L., et al. (2009). Brain-targeting gene delivery and cellular internalization mechanisms for modified rabies virus glycoprotein RVG29 nanoparticles. Biomaterials 30, 4195-4202. doi: 10.1016/j. biomaterials.2009.02.051

Liu, Y., Li, J., Shao, K., Huang, R., Ye, L., Lou, J., et al. (2010). A leptin derived 30-amino-acid peptide modified pegylated poly-l-lysine dendrigraft for brain targeted gene delivery. Biomaterials 31, 5246-5257. doi: 10.1016/j.biomaterials. 2010.03.011

Louveau, A., Smirnov, I., Keyes, T. J., Eccles, J. D., Rouhani, S. J., Peske, J. D., et al. (2015). Structural and functional features of central nervous system lymphatic vessels. Nature 523, 337-341. doi: 10.1038/nature14432

Lu, W., Sun, Q., Wan, J., She, Z., and Jiang, X. G. (2006). Cationic albumin - conjugated pegylated nanoparticles allow gene delivery into brain tumors via intravenous administration. Cancer Res. 66, 11878-11887. doi: 10. 1158/0008-5472.can-06-2354

MacKay, J. A., Li, W., Huang, Z., Dy, E. E., Huynh, G., Tihan, T., et al. (2008). HIV TAT peptide modifies the distribution of DNA nanolipoparticles following convection-enhanced delivery. Mol. Ther. 16, 893-900. doi: 10.1038/mt.2008. 36

Maheshri, N., Koerber, J. T., Kaspar, B. K., and Schaffer, D. V. (2006). Directed evolution of adeno-associated virus yields enhanced gene delivery vectors. Nat. Biotechnol. 24, 198-204. doi: 10.1038/nbt1182

Mano, Y., Saito, R., Haga, Y., Matsunaga, T., Zhang, R., Chonan, M., et al. (2016). Intraparenchymal ultrasound application and improved distribution of infusate with convection-enhanced delivery in rodent and nonhuman primate brain. J. Neurosurg. 124, 1490-1500. doi: 10.3171/2015.3.jns142152

Masserdotti, G., Gillotin, S., Sutor, B., Drechsel, D., Irmler, M., Jørgensen, H. F., et al. (2015). Transcriptional mechanisms of proneural factors and REST in regulating neuronal reprogramming of astrocytes. Cell Stem Cell 17, 74-88. doi: $10.1016 /$ j.stem.2015.05.014
Matsuoka, N., Nozaki, K., Takagi, Y., Nishimura, M., Hayashi, J., Miyatake, S.-I., et al. (2003). Adenovirus-mediated gene transfer of fibroblast growth factor-2 increases BrdU-positive cells after forebrain ischemia in gerbils. Stroke 34, 1519-1525. doi: 10.1161/01.str.0000070840.56414.3b

Mattson, M. P., and Magnus, T. (2006). Ageing and neuronal vulnerability. Nat. Rev. Neurosci. 7, 278-294. doi: 10.1038/nrn 1886

McDannold, N., Arvanitis, C. D., Vykhodtseva, N., and Livingstone, M. S. (2012). Temporary disruption of the blood-brain barrier by use of ultrasound and microbubbles: safety and efficacy evaluation in rhesus macaques. Cancer Res. 72, 3652-3663. doi: 10.1158/0008-5472.can-12-0128

Mead, B. P., Mastorakos, P., Suk, J. S., Klibanov, A. L., Hanes, J., and Price, R. J. (2016). Targeted gene transfer to the brain via the delivery of brain-penetrating DNA nanoparticles with focused ultrasound. J. Control. Release 223, 109-117. doi: 10.1016/j.jconrel.2015.12.034

Meairs, S., and Alonso, A. (2007). Ultrasound, microbubbles and the blood-brain barrier. Prog. Biophys. Mol. Biol. 93, 354-362. doi: 10.1016/j.pbiomolbio.2006. 07.019

Medina-Kauwe, L. K. (2007). "Alternative" endocytic mechanisms exploited by pathogens: new avenues for therapeutic delivery? Adv. Drug Deliv. Rev. 59, 798-809. doi: 10.1016/j.addr.2007.06.009

Mitchell, J. D., and Borasio, G. D. (2007). Amyotrophic lateral sclerosis. Lancet 369, 2031-2041. doi: 10.1016/S0140-6736(07)60944-1

Monani, U. R. (2005). Spinal muscular atrophy: a deficiency in a ubiquitous protein; a motor neuron-specific disease. Neuron 48, 885-896. doi: 10.1016/j. neuron.2005.12.001

Morille, M., Passirani, C., Vonarbourg, A., Clavreul, A., and Benoit, J. P. (2008). Progress in developing cationic vectors for non-viral systemic gene therapy against cancer. Biomaterials 29, 3477-3496. doi: 10.1016/j.biomaterials.2008. 04.036

Mortazavi, M. M., Griessenauer, C. J., Adeeb, N., Deep, A., Shahripour, R. B., Loukas, M., et al. (2014). The choroid plexus: a comprehensive review of its history, anatomy, function, histology, embryology and surgical considerations. Childs Nerv. Syst. 30, 205-214. doi: 10.1007/s00381-013-2326-y

Nance, E., Timbie, K., Miller, G. W., Song, J., Louttit, C., Klibanov, A. L., et al. (2014). Non-invasive delivery of stealth, brain-penetrating nanoparticles across the blood-Brain barrier using MRI-guided focused ultrasound. J. Control. Release 189, 123-132. doi: 10.1016/j.jconrel.2014.06.031

Nicholson, C., Kamali-Zare, P., and Tao, L. (2011). Brain extracellular space as a diffusion barrier. Comput. Vis. Sci. 14, 309-325. doi: 10.1007/s00791-0120185-9

Niidome, T., and Huang, L. (2002). Gene therapy progress and prospects: nonviral vectors. Gene Ther. 9, 1647-1652. doi: 10.1038/sj.gt.3301923

Pack, D. W., Hoffman, A. S., Pun, S., and Stayton, P. S. (2005). Design and development of polymers for gene delivery. Nat. Rev. Drug Discov. 4, 581-593. doi: 10.1038/nrd1775

Panje, C. M., Wang, D. S., and Willmann, J. K. (2013). Ultrasound and microbubble-mediated gene delivery in cancer: progress and perspectives. Invest. Radiol. 48, 755-769. doi: 10.1097/RLI.0b013e3182982cc1

Pardridge, W. M. (2005). The blood-brain barrier: bottleneck in brain drug development. NeuroRx 2, 3-14. doi: 10.1007/bf03206638

Pardridge, W. M. (2011). Drug transport in brain via the cerebrospinal fluid. Fluids Barriers CNS 8:7. doi: 10.1186/2045-8118-8-7

Park, T. E., Singh, B., Li, H., Lee, J. Y., Kang, S. K., Choi, Y. J., et al. (2015). Enhanced BBB permeability of osmotically active poly(mannitol-co-PEI) modified with rabies virus glycoprotein via selective stimulation of caveolar endocytosis for RNAi therapeutics in Alzheimer's disease. Biomaterials 38, 61-71. doi: 10.1016/j.biomaterials.2014.10.068

Patel, M., Goyal, B., Bhadada, S., Bhatt, J., and Amin, A. (2009). Getting into the brain. CNS Drugs 23, 35-58. doi: 10.2165/0023210-200923010-00003

Patlak, C. S., Blasberg, R. G., and Fenstermacher, J. D. (1983). Graphical evaluation of blood-to-brain transfer constants from multiple-time uptake data. J. Cereb. Blood Flow Metab. 3, 1-7. doi: 10.1038/jcbfm.1983.1

Petruska, J. C., Kitay, B., Boyce, V. S., Kaspar, B. K., Pearse, D. D., Gage, F. H., et al. (2010). Intramuscular AAV delivery of NT-3 alters synaptic transmission to motoneurons in adult rats. Eur. J. Neurosci. 32, 997-1005. doi: 10.1111/j. 1460-9568.2010.07392.x

Polikov, V. S., Tresco, P. A., and Reichert, W. M. (2005). Response of brain tissue to chronically implanted neural electrodes. J. Neurosci. Methods 148, 1-18. doi: 10. 1016/j.jneumeth.2005.08.015 
Pombo García, K., Zarschler, K., Barbaro, L., Barreto, J. A., O’Malley, W., Spiccia, L., et al. (2014). Zwitterionic-coated "stealth" nanoparticles for biomedical applications: recent advances in countering biomolecular corona formation and uptake by the mononuclear phagocyte system. Small 10, 2516-2529. doi: 10.1002/smll.201303540

Potts, M. B., Silvestrini, M. T., and Lim, D. A. (2013). Devices for cell transplantation into the central nervous system: design considerations and emerging technologies. Surg. Neurol. Int. 4, S22-S30. doi: 10.4103/2152-7806. 109190

Price, D., Griffin, J., Young, A., Peck, K., and Stocks, A. (1975). Tetanus toxin: direct evidence for retrograde intraaxonal transport. Science 188, 945-947. doi: $10.1126 /$ science. 49080

Pulford, B., Reim, N., Bell, A., Veatch, J., Forster, G., Bender, H., et al. (2010). Liposome-siRNA-peptide complexes cross the blood-brain barrier and significantly decrease PrPC on neuronal cells and PrPRES in infected cell cultures. PLoS One 5:e11085. doi: 10.1371/journal.pone.0011085

Qian, Y., Zha, Y., Feng, B., Pang, Z., Zhang, B., Sun, X., et al. (2013). PEGylated poly(2-(dimethylamino) ethyl methacrylate)/DNA polyplex micelles decorated with phage-displayed TGN peptide for brain-targeted gene delivery. Biomaterials 34, 2117-2129. doi: 10.1016/j.biomaterials.2012.11.050

Querbes, W., Ge, P., Zhang, W., Fan, Y., Costigan, J., Charisse, K., et al. (2009). Direct CNS delivery of siRNA mediates robust silencing in oligodendrocytes. Oligonucleotides 19, 23-30. doi: 10.1089/oli.2008.0165

Rapoport, S. I. (2001). Advances in osmotic opening of the blood-brain barrier to enhance CNS chemotherapy. Expert Opin. Investig. Drugs 10, 1809-1818. doi: 10.1517/13543784.10.10.1809

Rungta, R. L., Choi, H. B., Lin, P. J., Ko, R. W., Ashby, D., Nair, J., et al. (2013). Lipid nanoparticle delivery of siRNA to silence neuronal gene expression in the brain. Mol. Ther. Nucleic Acids 2:e136. doi: 10.1038/mtna.2013.65

Rychak, J. J., and Klibanov, A. L. (2014). Nucleic acid delivery with microbubbles and ultrasound. Adv. Drug Deliv. Rev. 72, 82-93. doi: 10.1016/j.addr.2014. 01.009

Salinas, S., Schiavo, G., and Kremer, E. J. (2010). A hitchhiker's guide to the nervous system: the complex journey of viruses and toxins. Nat. Rev. Microbiol. 8, 645-655. doi: 10.1038/nrmicro2395

Schellinger, J. G., Pahang, J. A., Johnson, R. N., Chu, D. S. H., Sellers, D. L., Maris, D. O., et al. (2013). Melittin-grafted HPMA-oligolysine based copolymers for gene delivery. Biomaterials 34, 2318-2326. doi: 10.1016/j. biomaterials.2012.09.072

Schöttler, S., Becker, G., Winzen, S., Steinbach, T., Mohr, K., Landfester, K., et al. (2016). Protein adsorption is required for stealth effect of poly(ethylene glycol)and poly(phosphoester)-coated nanocarriers. Nat. Nanotechnol. 11, 372-377. doi: 10.1038/nnano.2015.330

Schwab, M. E., Suda, K., and Thoenen, H. (1979). Selective retrograde synaptic transer of a protein, tetanus toxin, subsequent to its retrotransport. J. Cell Biol. 82, 798-810. doi: 10.1083/jcb.82.3.798

Sellers, D. L., Bergen, J. M., Johnson, R. N., Back, H., Ravits, J. M., and Horner, P. J. (2016). Targeted axonal import (TAxI) peptide delivers functional proteins into the spinal cord motor neurons after peripheral administration. Proc. Natl. Acad. Sci. U S A 113, 2514-2519. doi: 10.1073/pnas.15155 26113

Sheikov, N., McDannold, N., Vykhodtseva, N., Jolesz, F., and Hynynen, K. (2004). Cellular mechanisms of the blood-brain barrier opening induced by ultrasound in presence of microbubbles. Ultrasound Med. Biol. 30, 979-989. doi: 10.1016/j. ultrasmedbio.2004.04.010

Snyder, B. R., Gray, S. J., Quach, E. T., Huang, J. W., Leung, C. H., Samulski, R. J., et al. (2011). Comparison of adeno-associated viral vector serotypes for spinal cord and motor neuron gene delivery. Hum. Gene Ther. 22, 1129-1135. doi: 10. 1089/hum.2011.008

Soderquist, R., Sloane, E., Loram, L., Harrison, J., Dengler, E., Johnson, S., et al. (2010). Release of Plasmid DNA-encoding IL-10 from PLGA microparticles facilitates long-term reversal of neuropathic pain following a single intrathecal administration. Pharm. Res. 27, 841-854. doi: 10.1007/s11095-010$0077-y$

Song, H. P., Yang, J. Y., Lo, S. L., Wang, Y., Fan, W. M., Tang, X. S., et al. (2010). Gene transfer using self-assembled ternary complexes of cationic magnetic nanoparticles, plasmid DNA and cell-penetrating tat peptide. Biomaterials 31, 769-778. doi: 10.1016/j.biomaterials.2009.09.085
Son, S., Hwang, D. W., Singha, K., Jeong, J. H., Park, T. G., Lee, D. S., et al. (2011). RVG peptide tethered bioreducible polyethylenimine for gene delivery to brain. J. Control. Release 155, 18-25. doi: 10.1016/j.jconrel.2010.08.011

Spencer, B. J., and Verma, I. M. (2007). Targeted delivery of proteins across the blood-brain barrier. Proc. Natl. Acad. Sci. U S A 104, 7594-7599. doi: 10. 1073/pnas.0702170104

Stiles, D. K., Zhang, Z., Ge, P., Nelson, B., Grondin, R., Ai, Y., et al. (2012). Widespread suppression of huntingtin with convection-enhanced delivery of siRNA. Exp. Neurol. 233, 463-471. doi: 10.1016/j.expneurol.2011. 11.020

Sugiura, S., Kitagawa, K., Tanaka, S., Todo, K., Omura-Matsuoka, E., Sasaki, T., et al. (2005). Adenovirus-mediated gene transfer of heparin-binding epidermal growth factor-like growth factor enhances neurogenesis and angiogenesis after focal cerebral ischemia in rats. Stroke 36, 859-864. doi: 10.1161/01.str. 0000158905.22871 .95

Syková, E., and Nicholson, C. (2008). Diffusion in brain extracellular space. Physiol. Rev. 88, 1277-1340. doi: 10.1152/physrev.00027.2007

Tan, J.-K. Y., Pham, B., Zong, Y., Perez, C., Maris, D. O., Hemphill, A., et al. (2016). Microbubbles and ultrasound increase intraventricular polyplex gene transfer to the brain. J. Control. Release 231, 86-93. doi: 10.1016/j.jconrel.2016. 02.003

Tang, G. P., Zeng, J. M., Gao, S. J., Ma, Y. X., Shi, L., Li, Y., et al. (2003). Polyethylene glycol modified polyethylenimine for improved CNS gene transfer: effects of PEGylation extent. Biomaterials 24, 2351-2362. doi: 10. 1016/s0142-9612(03)00029-2

Tarragó-Trani, M. T., and Storrie, B. (2007). Alternate routes for drug delivery to the cell interior: pathways to the Golgi apparatus and endoplasmic reticulum. Adv. Drug Deliv. Rev. 59, 782-797. doi: 10.1016/j.addr.2007. 06.006

Thomas, C. E., Ehrhardt, A., and Kay, M. A. (2003). Progress and problems with the use of viral vectors for gene therapy. Nat. Rev. Genet. 4, 346-358. doi: 10. 1038/nrg1066

Tobinick, E. L. (2016). Perispinal delivery of CNS drugs. CNS Drugs 30, 469-480. doi: 10.1007/s40263-016-0339-2

Uchida, S., Itaka, K., Uchida, H., Hayakawa, K., Ogata, T., Ishii, T., et al. (2013). in vivo messenger RNA introduction into the central nervous system using polyplex nanomicelle. PLoS One 8:e56220. doi: 10.1371/journal.pone. 0056220

von Bartheld, C. S. (2004). Axonal transport and neuronal transcytosis of trophic factors, tracers and pathogens. J. Neurobiol. 58, 295-314. doi: 10.1002/neu. 10315

Wang, H., Ghosh, A., Baigude, H., Yang, C. S., Qiu, L., Xia, X., et al. (2008). Therapeutic gene silencing delivered by a chemically modified small interfering RNA against mutant SOD1 slows amyotrophic lateral sclerosis progression. J. Biol. Chem. 283, 15845-15852. doi: 10.1074/jbc.m800834200

Wehling, K., Arfmann, H.-A., Standke, K.-H. C., and Wagner, K. G. (1975). Specfificity of DNA-basic polypeptide interactions. Influence of neutral residues incorporated into polylysine and polyarginine. Nucleic Acids Res. 2, 799-807. doi: 10.1093/nar/2.6.799

Wei, H., Volpatti, L. R., Sellers, D. L., Maris, D. O., Andrews, I. W., Hemphill, A. S., et al. (2013). Dual responsive, stabilized nanoparticles for efficient in vivo plasmid delivery. Angew. Chem. Int. Ed Engl. 52, 5377-5381. doi: 10.1002/anie. 201301896

Xie, F., Boska, M. D., Lof, J., Uberti, M. G., Tsutsui, J. M., and Porter, T. R. (2008). Effects of transcranial ultrasound and intravenous microbubbles on blood brain barrier permeability in a large animal model. Ultrasound Med. Biol. 34, 2028-2034. doi: 10.1016/j.ultrasmedbio.2008.05.004

Xu, J., Ma, C., Bass, C., and Terwilliger, E. F. (2005). A combination of mutations enhances the neurotropism of AAV-2. Virology 341, 203-214. doi: 10.1016/j. virol.2005.06.051

Yamada, K., Ushio, Y., Hayakawa, T., Kato, A., Yamada, N., and Mogami, H. (1982). Quantitative autoradiographic measurements of blood-brain barrier permeability in the rat glioma model. J. Neurosurg. 57, 394-398. doi: 10. 3171/jns.1982.57.3.0394

Yao, H., Wang, K., Wang, Y., Wang, S., Li, J., Lou, J., et al. (2015). Enhanced blood-brain barrier penetration and glioma therapy mediated by a new peptide modified gene delivery system. Biomaterials 37, 345-352. doi: 10.1016/j. biomaterials.2014.10.034 
Yue, P., He, L., Qiu, S., Li, Y., Liao, Y., Li, X., et al. (2014). OX26/CTX-conjugated PEGylated liposome as a dual-targeting gene delivery system for brain glioma. Mol. Cancer 13:191. doi: 10.1186/1476-4598-13-191

Yu, Y. J., Zhang, Y., Kenrick, M., Hoyte, K., Luk, W., Lu, Y., et al. (2011). Boosting brain uptake of a therapeutic antibody by reducing its affinity for a transcytosis target. Sci. Transl. Med. 3:84ra44. doi: 10.1126/scitranslmed.3002230

Zeng, J., Wang, X., and Wang, S. (2007). Self-assembled ternary complexes of plasmid DNA, low molecular weight polyethylenimine and targeting peptide for nonviral gene delivery into neurons. Biomaterials 28, 1443-1451. doi: 10. 1016/j.biomaterials.2006.11.015

Zhang, Y., Pak, C., Han, Y., Ahlenius, H., Zhang, Z., Chanda, S., et al. (2013). Rapid single-step induction of functional neurons from human pluripotent stem cells. Neuron 78, 785-798. doi: 10.1016/j.neuron.2013.05.029

Zhang, Y., Wang, Y., Boado, R. J., and Pardridge, W. M. (2008). Lysosomal enzyme replacement of the brain with intravenous non-viral gene transfer. Pharm. Res. 25, 400-406. doi: 10.1007/s11095-007-9357-6
Zhou, Y., Yang, K., Cui, J., Ye, J., and Deng, C. (2012). Controlled permeation of cell membrane by single bubble acoustic cavitation. J. Control. Release 157, 103-111. doi: 10.1016/j.jconrel.2011.09.068

Zou, S., Scarfo, K., Nantz, M. H., and Hecker, J. G. (2010). Lipid-mediated delivery of RNA is more efficient than delivery of DNA in non-dividing cells. Int. J. Pharm. 389, 232-243. doi: 10.1016/j.ijpharm.2010.01.019

Conflict of Interest Statement: Authors have a US patent $(61 / 532,982)$ regarding TAxI peptide.

Copyright (C) 2016 Tan, Sellers, Pham, Pun and Horner. This is an open-access article distributed under the terms of the Creative Commons Attribution License (CC BY). The use, distribution and reproduction in other forums is permitted, provided the original author(s) or licensor are credited and that the original publication in this journal is cited, in accordance with accepted academic practice. No use, distribution or reproduction is permitted which does not comply with these terms. 